\title{
Analysis on Cooling Effect of Crushed-Rocks Embankment of Qinghai-Tibet High-Grade Road
}

\author{
Dongqing Li, ${ }^{1}$ Kun Zhang, ${ }^{1,2}$ Gangqiang Tong, ${ }^{3}$ Feng Ming, ${ }^{1}$ and Xing Huang \\ ${ }^{1}$ State Key Laboratory of Frozen Soil Engineering, Cold and Arid Regions Environmental and Engineering Research Institute, \\ Chinese Academy of Sciences, Lanzhou 730000, China \\ ${ }^{2}$ Gansu Provincial Transportation Research Institute Co., Ltd., Lanzhou 730050, China \\ ${ }^{3}$ Tianjin Metro Limited Company, Tianjin 300051, China
}

Correspondence should be addressed to Dongqing Li; dqli@lzb.ac.cn

Received 30 September 2014; Accepted 2 March 2015

Academic Editor: Azah Mohamed

Copyright (C) 2015 Dongqing Li et al. This is an open access article distributed under the Creative Commons Attribution License, which permits unrestricted use, distribution, and reproduction in any medium, provided the original work is properly cited.

In order to study the cooling effect of the crushed-rocks embankment, the permeability and the inertial resistance coefficient were measured by the wind tunnel test of spheres with a diameter of $20 \mathrm{~cm}$, and then the stabilities of the closed crushed-rocks embankment with the wide pavement, the closed crushed-rocks embankment with the narrow pavement, and the duct-ventilated and closed crushed-rocks embankment were calculated. In the next 50 years, assuming that the temperature in Qinghai-Tibet plateau will rise by $2.6^{\circ} \mathrm{C}$ condition, the cooling effects of these three special high-grade embankment structures were studied. The test results and the numerical calculation results show that the relationship between pressure gradient and seepage velocity in the spheres layer diverges completely from Darcy's law, and it shows a nice quadratic nonlinear relationship. Stabilities of those two closed crushed-rock embankments without the duct-ventilated structure could be destroyed because of the high permafrost temperature under embankments. The duct-ventilated and closed crushed-rocks embankment can cool down the permafrost effectively and raise the permafrost table and ensure the long-term thermal stability of permafrost under road.

\section{Introduction}

The crushed-rocks embankment has been widely applied in permafrost road engineering. Existing field tests and practical engineering applications show that the crushedrocks embankment can provide a better cooling effect $[1,2]$, and large amount of test data provides reference for the design [3-5] and understanding of the cooling characteristics of the engineering structure [6-8]. Indoor model tests of various scales and structures have helped understand the cooling mechanism of the crushed-rocks. Forced convective heat transfer mostly occurs in open crushed-rocks, which, when in cold seasons, due to high density of cold air, squeezes hot air out of the ventilation tunnel under the effect of gravity and wind, constantly taking away heat from surrounding soil, effectively protecting the permafrost. Closed crushedrocks, which mainly experience natural convective heat transfer, when in warm seasons, cause hot air to move up due to surface heat. Closed crushed-rocks act as a effective thermal barrier, make the air inside of it at a thermally conductive state, and prevent heat penetrating into the deeper permafrost. Internal air experiences different densities due to temperature upwards higher than that of downwards in cold seasons, which cause natural convective heat transfer of the air inside, eventually cooling down the embankment [9].

Currently, mathematical models about closed crushedrocks embankment are primarily based on continuity equation in porous materials, energy equation, non-Darcy momentum equation, and Boussinesq approximation. Halfempirical formulae are often used to calculate the permeability and the inertial friction coefficient in non-Darcy momentum equation [10]; however, significant differences may occur, compared with observed data. In practice, this could change the convective properties of air, further affecting the temperature field distribution characteristics of the whole embankment. This paper used wind tunnel test and obtained the permeability and the inertial friction coefficient of cubic packed spheres and applied them into the numerical 


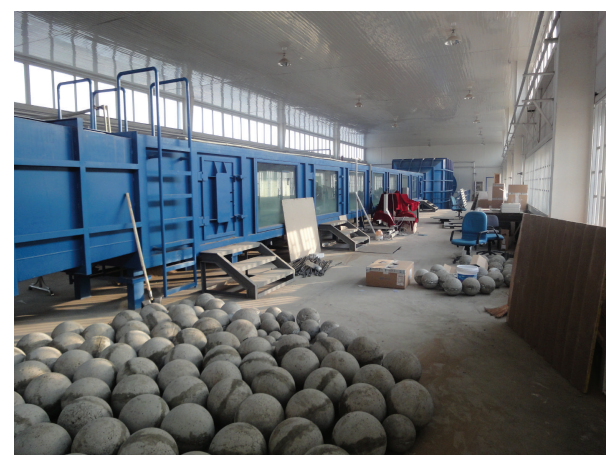

(a)

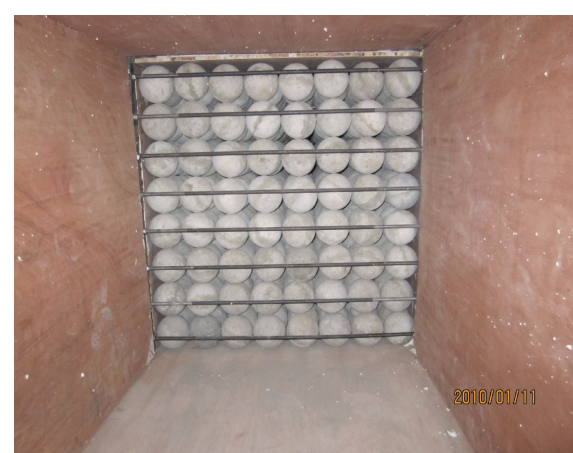

(b)

FIGURE 1: The wind tunnel facility and laying mode of spheres.

analysis for crushed-rocks embankment along Qinghai-Tibet high-grade road. The research work to study the cooling effect and the temperature field characteristics of the crushed-rocks embankment under asphalt road on the condition of climate warming provides scientific evidence for the construction of high-grade road in Qinghai-Tibet plateau permafrost areas.

\section{Mathematical Model and Indoor Experiments}

Closed crushed-rocks area of embankment can be considered to be a porous medium, where, when external temperatures start to change, the air inside rocks could experience natural convection. Porous medium experiences a nonisothermal and nonsteady natural convection, so the continuity equation, momentum equation, energy equation, and Boussinesq approximation [11-13] were listed as follows:

continuity equation:

$$
\frac{\partial u}{\partial x}+\frac{\partial v}{\partial y}+\frac{\partial w}{\partial z}=0
$$

momentum equation:

$$
\begin{aligned}
& \frac{\partial p}{\partial x}=-\frac{\mu}{k} v_{x}-\rho B|\mathbf{v}| v_{x}, \\
& \frac{\partial p}{\partial y}=-\frac{\mu}{k} v_{y}-\rho B|\mathbf{v}| v_{y}-\rho_{0}\left[1-\beta\left(T-T_{0}\right)\right], \\
& \frac{\partial p}{\partial z}=-\frac{\mu}{k} v_{z}-\rho B|\mathbf{v}| v_{z}
\end{aligned}
$$

energy equation:

$$
\begin{array}{r}
\left(\rho c_{p}\right)_{t} \frac{\partial T}{\partial t}+\frac{\partial\left(\rho c_{p} u T\right)}{\partial x}+\frac{\partial\left(\rho c_{p} v T\right)}{\partial y}+\frac{\partial\left(\rho c_{p} w T\right)}{\partial z} \\
=\frac{\partial}{\partial x}\left(\lambda_{t} \frac{\partial T}{\partial x}\right)+\frac{\partial}{\partial y}\left(\lambda_{t} \frac{\partial T}{\partial y}\right)+\frac{\partial}{\partial z}\left(\lambda_{t} \frac{\partial T}{\partial z}\right)
\end{array}
$$

where $\mathbf{v}$ is the velocity vector, $u, v, w$, respectively, are velocity components, $x, y, z$, respectively, are coordinate components, $p$ is the pressure, $\mu$ is the dynamic viscosity for air, $k$ is the permeability, $B$ is the inertial resistance coefficient of air, $T, T_{0}$, respectively are the instantaneous temperature and the initial reference temperature, $\rho, \rho_{0}$, respectively, are the instantaneous air density and the initial reference air density, $c_{p}$ is the specific heat at constant pressure, and $\lambda_{t}$ is the instantaneous thermal conductivity.

Based on apparent heat capacity method, obtained the valid heat conduction coefficient and the heat capacity. This is a 3-dimensional nonlinear problem; therefore discrete equations based on finite-volume method were established, and the numerical solution is got through using SIMPLE algorithm to solve the discrete equations [14].

Crushed-rocks have uncommon shapes and are usually randomly placed; hence, it is difficult to measure its permeability and inertial resistance coefficient. To find the values for a $20 \mathrm{~cm}$ crushed-rock, our research makes use of $20 \mathrm{~cm}$ cement sphere in a wind tunnel experiment, where the boundary wind speed condition is given based on the average wind speed in Qinghai-Tibet permafrost regions. The wind tunnel works vertically downwards, consisting of initiation, rectification, experimentation, and extension section. The tunnel is $55.00 \mathrm{~m}$ long, with experiment section being $20.00 \mathrm{~m}$ long, and the cross sectional area is $1.3 \mathrm{~m}$ (width) $\times 1.45 \mathrm{~m}$ (height). Wind speed is variable from $4 \mathrm{~m} / \mathrm{s}$ to $40 \mathrm{~m} / \mathrm{s}$. Detail setup of the apparatus is shown in Figures 1(a) and 1(b).

Figure 2 shows the relationship between the pressure gradient and seepage velocity of sphere layer, for spheres of $20 \mathrm{~cm}$. Their exact relationship is as follows:

$$
\frac{\partial P}{\partial L}=0.53 V+30.63 V^{2},
$$

where $P$ is pressure, $L$ is the experiment section length, and $V$ is measured velocity. It can be seen from the equation that the relationship between pressure gradient and seepage velocity has completely deviated from Darcy's law, showing a nice second-order nonlinear relationship, correlating with the relationship proposed by Forchheimer [15]. Cubic packed spheres have a large porosity and larger seepage velocity. It 


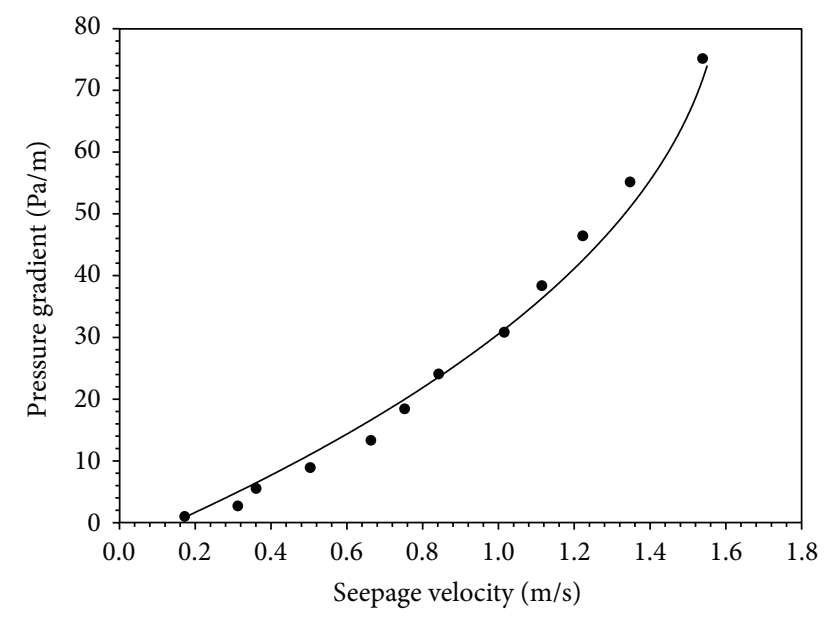

Figure 2: The relationship between pressure gradient and seepage velocity of spheres layer with diameters of $20 \mathrm{~cm}$.

is insufficient to take account of only viscous friction, hence requiring us to add inertial friction force. Thus, (4) can be described as

$$
\frac{\partial P}{\partial L}=\frac{\mu}{k} V+B \rho V^{2}
$$

where $\mu$ is the dynamic viscosity for air, $\mu=1.72 \times 10^{-5} \mathrm{P}_{\mathrm{a}}$. $s$, and $\rho$ is air density [16]. The ambient temperate and pressure can be measured during the experiment, and the experimental air density can be calculated according to the air state equation. The air state equation was described as

$$
\rho=\frac{\rho_{0} T_{0} P}{P_{0} T} .
$$

Through the calculation, the permeability $k$ is $3.25 \times$ $10^{-5} \mathrm{~m}^{2}$ for $20 \mathrm{~cm}$ (diameter) cement spheres, and the inertial resistance coefficient $B 28.9 \mathrm{~m}^{-1}$ was obtained. As you know, the porosity of spheres layer for the regular arrangement is a given number; that is, $n=4.764$; thus, if the shape factors for spheres layer and crushed-rocks layer were approximated as a constant under the same diameter and average diameter, the permeability $k^{\prime}$ and the inertial resistance coefficient $B^{\prime}$ for in situ crushed-rocks layer (the average diameter is $20 \mathrm{~cm}$ ) could be derived as follows [17]:

$$
\begin{aligned}
& k^{\prime}=\frac{\left(n^{\prime}\right)^{3}(1-n)^{2}}{\left(1-n^{\prime}\right)^{2} n^{3}}, \\
& B^{\prime}=\frac{\left(1-n^{\prime}\right)(n)^{3}}{(1-n)\left(n^{\prime}\right)^{3}},
\end{aligned}
$$

where $n^{\prime}$ is the measured porosity for in situ crushed-rocks layer and $n^{\prime}=0.41$ (the average diameter of crushed-rocks layer is $20 \mathrm{~cm}$ ); thus, $k^{\prime}$ and $B^{\prime}$, respectively, are $1.6316 \mathrm{~m}^{2}$ and $51.0874 \mathrm{~m}^{-1}$.

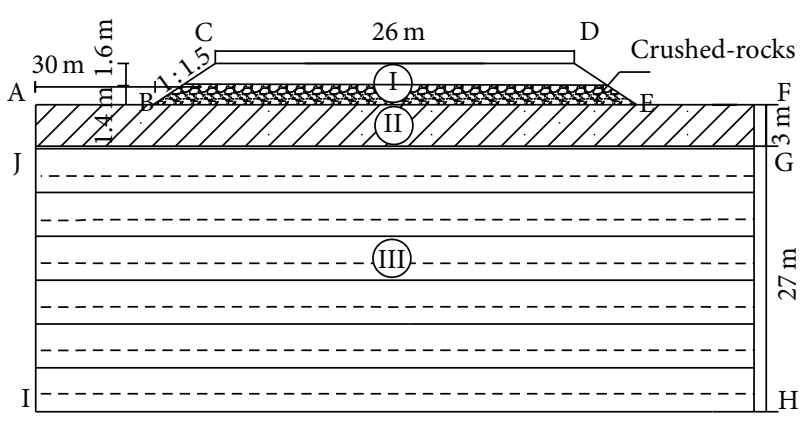

FIGURE 3: The model of the closed crushed-rocks embankment with the wide road pavement.

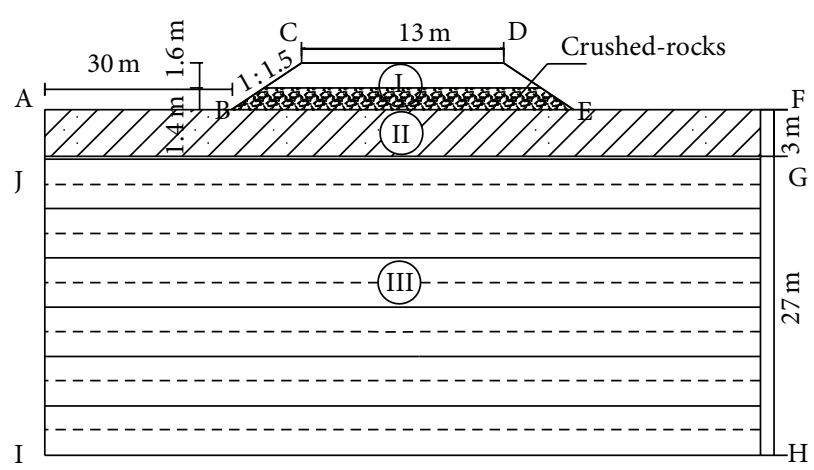

FIGURE 4: The model of the narrow closed crushed-rocks embankment.

\section{Area of Calculation and Boundary Conditions}

The test area of the Western Project Program of the Chinese Academy of Sciences, at an altitude of approximately $4700 \mathrm{~m}$, was used as the model for calculation. The domain of calculation is shown in Figures 3, 4, and 5. Assume an initial annual average temperature of $-4.0^{\circ} \mathrm{C}$; if we consider the temperature increase $2.6^{\circ} \mathrm{C}$ within the next 50 years, in the Qinghai-Tibet permafrost region, then, from the adherent layer theory [18], temperature for asphalt roads increases $6.5^{\circ} \mathrm{C}$. According to observation data from QinghaiTibet railway ventilation duct test [19], the average central temperature inside the ventilation duct is $1.8^{\circ} \mathrm{C}$ higher than ambient average. From the relative conclusions of previous researches $[5,7,20,21]$, we confirm the following boundary conditions.

Air temperature is governed by

$$
T_{q}=-4.0+11.5 \sin \left(\frac{2 \pi t}{8760}+\frac{\pi}{2}\right)+\frac{2.6 t}{438000} .
$$
by

Temperatures of natural ground $\mathrm{AB}$ and $\mathrm{EF}$ are governed

$$
T_{t}=-1.5+12 \sin \left(\frac{2 \pi t}{8760}+\frac{\pi}{2}\right)+\frac{2.6 t}{438000} .
$$


TABLE 1: Thermal parameters of various materials in and beneath the embankment.

\begin{tabular}{|c|c|c|c|c|c|}
\hline Physical parameters & $\begin{array}{l}\text { Heat conduction } \\
\text { coefficient for frozen soil } \\
\lambda_{f}\left(\mathrm{~W} /\left(\mathrm{m} \cdot{ }^{\circ} \mathrm{C}\right)\right)\end{array}$ & $\begin{array}{l}\text { Heat capacity for } \\
\text { frozen soil } \\
C_{f}\left(\mathrm{~J} /\left(\mathrm{m}^{3} \cdot{ }^{\circ} \mathrm{C}\right)\right)\end{array}$ & $\begin{array}{c}\text { Heat conduction } \\
\text { coefficient for unfrozen soil } \\
\lambda_{u}\left(\mathrm{~W} /\left(\mathrm{m} \cdot{ }^{\circ} \mathrm{C}\right)\right)\end{array}$ & $\begin{array}{l}\text { Heat capacity for } \\
\text { unfrozen soil } \\
C_{u}\left(\mathrm{~J} /\left(\mathrm{m}^{3} \cdot{ }^{\circ} \mathrm{C}\right)\right)\end{array}$ & $\begin{array}{l}\text { Latent heat } \\
L\left(\mathrm{~J} / \mathrm{m}^{3}\right)\end{array}$ \\
\hline Ventilation duct & 1.54 & $2.016 \times 10^{6}$ & 1.54 & $2.016 \times 10^{6}$ & 0 \\
\hline Crushed-rocks & 0.39 & $1.015 \times 10^{6}$ & 0.39 & $1.015 \times 10^{6}$ & 0 \\
\hline Gravel fill & 1.98 & $1.913 \times 10^{6}$ & 1.92 & $2.227 \times 10^{6}$ & $2.04 \times 10^{7}$ \\
\hline Silty clay & 1.35 & $1.879 \times 10^{6}$ & 1.13 & $2.357 \times 10^{6}$ & $6.03 \times 10^{7}$ \\
\hline Weathered mudstone & 1.82 & $1.846 \times 10^{6}$ & 1.48 & $2.099 \times 10^{6}$ & $3.77 \times 10^{7}$ \\
\hline
\end{tabular}

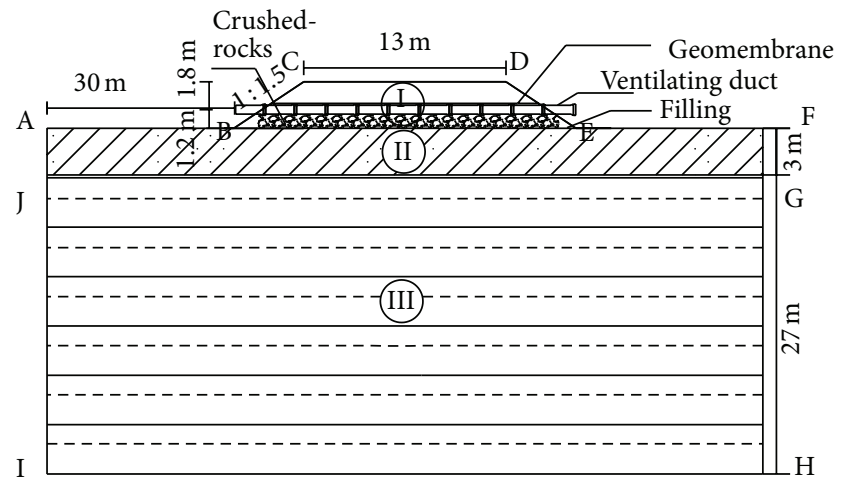

FIGURE 5: The model of the duct-ventilated and closed crushedrocks embankment.

Temperatures of slope BC and DE are governed by

$$
T_{p}=0.7+13 \sin \left(\frac{2 \pi t}{8760}+\frac{\pi}{2}\right)+\frac{2.6 t}{438000} .
$$

Temperature of asphalt pavement CD is governed by

$$
T_{l}=2.5+15 \sin \left(\frac{2 \pi t}{8760}+\frac{\pi}{2}\right)+\frac{2.6 t}{438000} .
$$

Temperature inside ventilation duct is governed by

$$
T_{g}=-2.2+11.5 \sin \left(\frac{2 \pi t}{8760}+\frac{\pi}{2}\right)+\frac{2.6 t}{438000},
$$

where $T$ is the temperatures $\left({ }^{\circ} \mathrm{C}\right)$ and $t$ is the time $(\mathrm{h})$.

The convective heat transfer coefficient between the air and the ventilation duct wall is $h=15.0 \mathrm{~W} \cdot \mathrm{m}^{-2} \cdot{ }^{\circ} \mathrm{C}^{-1}$ [22]. Heat flux density of the terrestrial heat through $\mathrm{IH}$ is $q=$ $0.06 \mathrm{~W} \cdot \mathrm{m}^{-2}$ and AJI and FGH can be considered adiabatic and assume no flow through the flow boundaries.

For an altitude of $4700 \mathrm{~m}$, the isobaric heat capacity for air is $C_{p}=1004 \mathrm{~J} \cdot \mathrm{kg}^{-1} \cdot{ }^{\circ} \mathrm{C}^{-1}$, conduction coefficient $\lambda=$ $0.02 \mathrm{~W} \cdot \mathrm{m}^{-1} \cdot{ }^{\circ} \mathrm{C}^{-1}$, density $\rho_{0}=0.641 \mathrm{~kg} \cdot \mathrm{m}^{-3}$, and viscosity $\mu=1.72 \times 10^{-5} \mathrm{~kg} \cdot \mathrm{m}^{-1} \cdot \mathrm{s}^{-1}$.

In Figures 3, 4, and 5, area $\mathrm{I}$ is embankment filling, area II is the silty clay, and area III is slightly weathered mudstone. The thermal characteristics are shown in Table 1. Average diameter for crushed-rocks is $20 \mathrm{~cm}$, permeability is $k^{\prime}=1.6316 \times 10^{-5} \mathrm{~m}^{2}$, and inertial resistance coefficient $B^{\prime}=51.0874 \mathrm{~m}^{-1}$. Figure 3 shows the calculation domain for closed crushed-rocks embankment with wide pavement. Embankment is $3 \mathrm{~m}$ in height and $26 \mathrm{~m}$ in width. And the calculation domain covers $30 \mathrm{~m}$ from the embankment slope ends and $30 \mathrm{~m}$ below natural ground and crushed-rocks area is $1.4 \mathrm{~m}$ thick. In order to look into its temperature field characteristics, it is assumed for numerical calculation that, in the next 50 years, the temperature in Qinghai-Tibet plateau will rise by $2.6^{\circ} \mathrm{C}$.

\section{Numerical Results and Discussions}

4.1. Temperature Field Characteristics of Closed CrushedRocks Embankment with Wide Pavement. Figure 6 shows the ground temperature distribution on the 50th year after construction of closed crushed-rocks embankment with wide pavement. From Figure 6(a), it can be seen that, on 15th of July, there is a clearly sunken profile of the $-0.25^{\circ} \mathrm{C}$ isothermal line under the embankment, and the line starts to rise near the slope. The phenomena may be due to two reasons: one is that wide pavement absorbs more heat; the other is that wide pavement results in weaker natural convective heat transfer near the centre of crushed-rocks. On 15th of October, Figure 6(b), natural permafrost table is $2.35 \mathrm{~m}$, the thaw depth of natural ground under central embankment is $0.69 \mathrm{~m}$, and $-0.25^{\circ} \mathrm{C}$ isothermal line drops. On $15 \mathrm{th}$ of January of the next year, the permafrost temperature under embankment continued to rise, compared to the previous 15 th of October, and $-0.25^{\circ} \mathrm{C}$ isothermal line continued to move downwards. Residual thawed layers emerged under natural ground; however, the embankment filling and the underneath permafrost all froze completely.

The analysis above indicates that, considering a $2.6^{\circ} \mathrm{C}$ temperature increase in the next 50 years, permafrost temperature under closed crushed-rocks embankment with wide pavement will be relatively high, increasing to around -0.25 in the 50th year, approaching $0^{\circ} \mathrm{C}$. Hence, for construction of high-grade roads in permafrost regions, it is not appropriate to use closed crushed-rocks embankment with wide pavement.

4.2. Temperature Field Characteristics of Closed CrushedRocks Embankment with Narrow Pavement. In the 50th year after construction of closed crushed-rocks embankment with wide pavement, permafrost under embankment has a high temperature, which may reduce stability of the embankment; hence it should be treated narrowly. Figure 4 is the calculation domain for the closed crushed-rocks embankment, in which, 


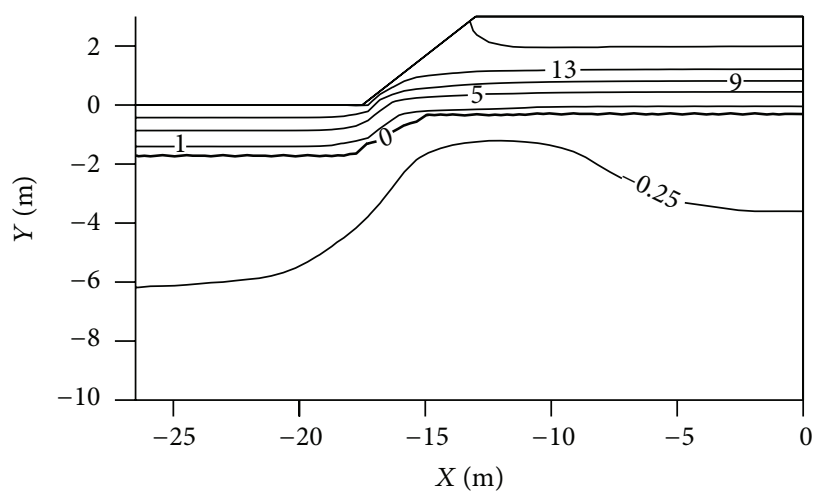

(a) 15th of July

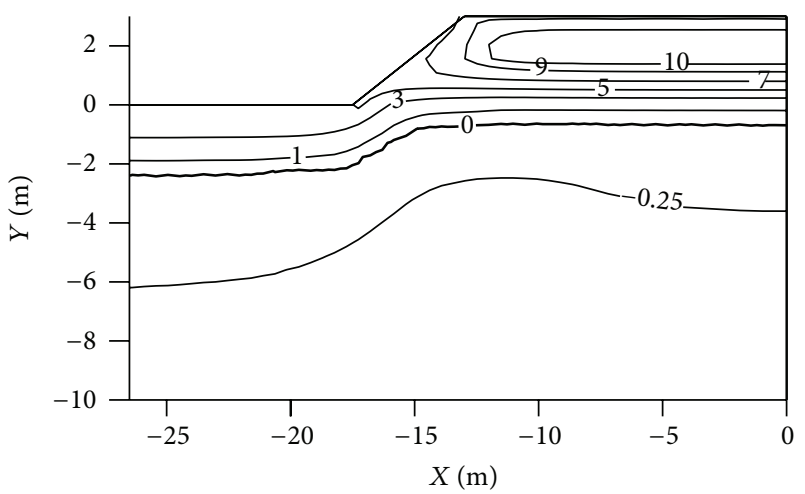

(b) 15th of October

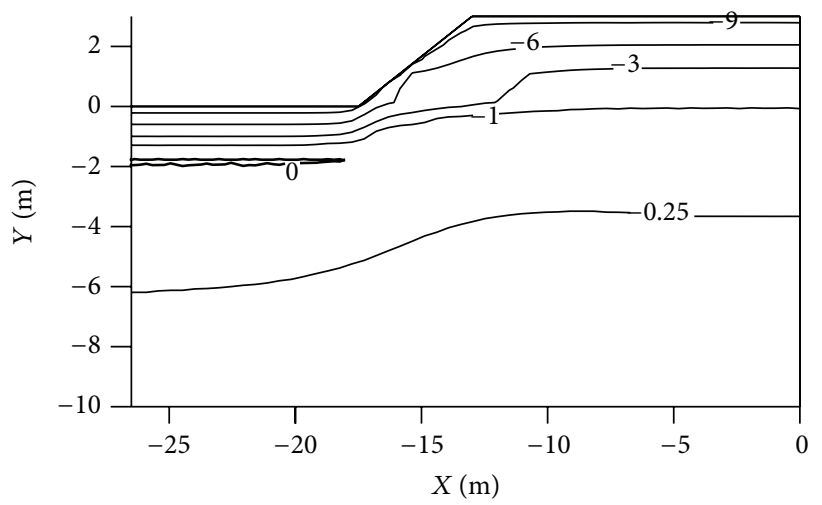

(c) 15 th of January

FiguRE 6: Temperature field of the closed crushed-rocks embankment with the wide pavement after 50 years of construction.

compared to Figure 3, only the surface width is halved, becoming $13 \mathrm{~m}$; other conditions do not change. In order to analyze its temperature field characteristics, it is assumed for numerical calculation that, in the next 50 years, the temperature in Qinghai-Tibet plateau will rise by $2.6^{\circ} \mathrm{C}$.

Figure 7 (a) shows the ground temperature field on 15 th of July, the 50th year after construction of closed crushed-rocks embankment with narrow pavement. It can be seen from the figure that the $-0.35^{\circ} \mathrm{C}$ freezing nuclei exist in the permafrost under embankment, and soil temperature is simultaneously lower than that in closed crushed-rocks embankment with wide pavement, especially with $-0.25^{\circ} \mathrm{C}$ isothermal line not showing a sunken profile under the embankment. This indicates that narrow pavement absorbs less heat, and there is a stronger natural convective heat transfer in central crushedrocks of embankment. On 15th of October, Figure 7(b), natural permafrost table is $2.35 \mathrm{~m}$; the thaw depth of the natural ground under the embankment central is $0.61 \mathrm{~m}$. Compared with Figure 7(a), soil temperature under embankment rose to around $-0.3^{\circ} \mathrm{C}$, which, however, is still lower than that for embankment with wide pavement. On 15th of January, the next year, Figure 7(c), although the embankment filling and permafrost underneath have returned to their frozen state, the permafrost temperature under embankment, compared to the previous 15 th of October, Figure 7(b), continues to rise, while the $-0.25^{\circ} \mathrm{C}$ and $-0.3^{\circ} \mathrm{C}$ isothermal lines move downwards.

The above analysis shows that, considering a $2.6^{\circ} \mathrm{C}$ temperature increase in the next 50 years, permafrost temperature under closed crushed-rocks embankment with narrow pavement will increase to around $-0.3^{\circ} \mathrm{C}$, which, although still a negative temperature, is already near $0^{\circ} \mathrm{C}$. To effectively ensure the thermal stability of embankment, additional protection measures are recommended, if considering the use of closed crushed-rocks embankment.

4.3. Temperature Field Characteristics of Duct-Ventilated and Closed Crushed-Rocks Embankment. For the two previous types of embankments, permafrost under the embankment has a high temperature in the 50th year. Therefore, in order to better protect the permafrost, ventilation ducts are deployed above the crushed-rocks, to further enhance the cooling effect of the embankment. Figure 5 shows the calculation domain for duct-ventilated and closed crushed-rocks embankment. Embankment is $3 \mathrm{~m}$ height and $13 \mathrm{~m}$ width and the calculation domain covers $30 \mathrm{~m}$ from the embankment slope ends and $30 \mathrm{~m}$ below natural ground and the crushed-rocks area is $1.4 \mathrm{~m}$ thick. Ventilation ducts are $0.4 \mathrm{~m}$ in diameter, with a distance of $1.2 \mathrm{~m}$ between centre lines of adjacent ducts, and $1.2 \mathrm{~m}$ away from natural ground. In order to look into its 


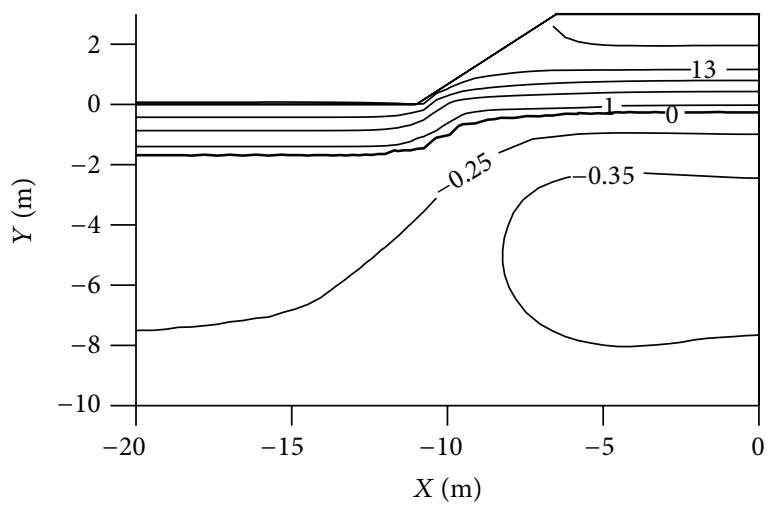

(a) 15 th of July

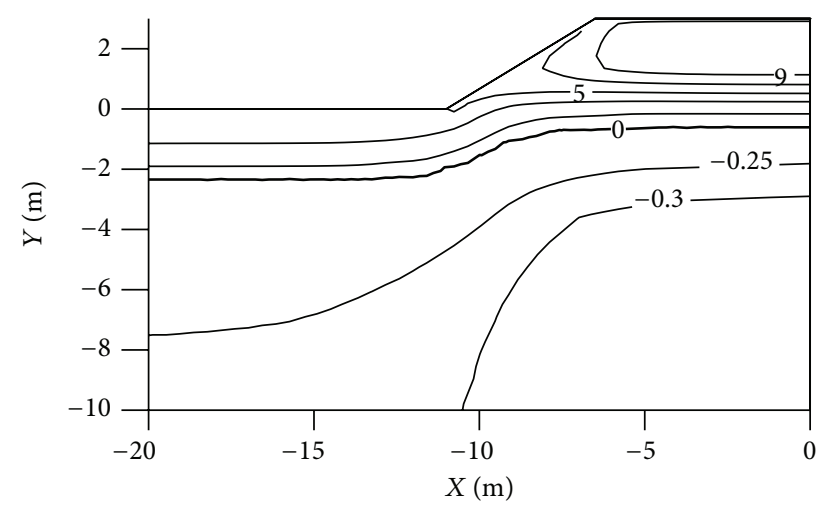

(b) 15th of October

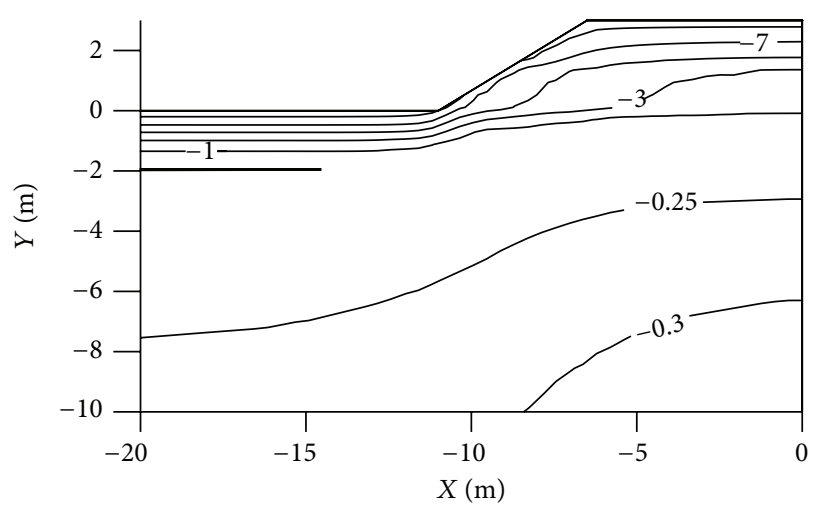

(c) 15 th of January

FIgURE 7: Temperature field of the closed crushed-rocks embankment with the narrow pavement after 50 years of construction.

cooling effect, it is assumed for numerical calculation that, in the next 50 years, the temperature in Qinghai-Tibet plateau will rise by $2.6^{\circ} \mathrm{C}$.

Figure 8 shows the temperature field of the duct-ventilated and closed crushed-rocks embankment after 50 years of construction. Comparing Figure 8(a) with Figure 7(a), permafrost temperature under the duct-ventilated and closed crushed-rocks embankment is lower by approximately $0.65^{\circ} \mathrm{C}$ than it is under the closed crushed-rocks embankment with narrow pavement, and $-1^{\circ} \mathrm{C}$ freezing nuclei exist in the embankment. On 15th of January, Figure 8(b), natural permafrost table is $2.35 \mathrm{~m}$, the thaw depth of the natural ground under the embankment central is $0.46 \mathrm{~m}$, and soil temperature under embankment is much lower than that for closed crushed-rocks embankment with narrow pavement, Figure $7(\mathrm{~b})$, and $-1^{\circ} \mathrm{C}$ freezing nuclei still exist in the embankment. On 15th of January, Figure 8(c), the next year, the permafrost temperature under embankment, compared to the previous 15th of October, Figure $8(\mathrm{~b})$, continues to rise, and residual thawed layers emerge under natural ground; however, the embankment filling and the permafrost underneath all freeze completely.

The above analysis shows that, considering a $2.6^{\circ} \mathrm{C}$ temperature increase in the next 50 years, duct-ventilated and closed crushed-rocks embankment can effectively cool down the permafrost temperature, increasing the nature table and ensuring long term thermal stability of the permafrost under the embankment. In consideration of large air temperature rises, to ensure the stability of the permafrost and normal functions of the road, the use of such embankment for asphalt high-grade roads in permafrost regions is recommended.

\section{Conclusions}

Based on data collected from the wind tunnel experiment using cement spheres, $20 \mathrm{~cm}$ in diameter, numerical calculation is completed for crushed-rocks embankment of the Qinghai-Tibet high-grade road, and we have come to the following conclusions.

(1) Relationship between the pressure gradient and seepage velocity of the internal spheres has completely deviated from Darcy's law, suggesting a valid secondorder nonlinear relationship. For cubic packed $20 \mathrm{~cm}$ spheres, permeability and inertial resistance coefficient are $3.25 \times 10^{-5} \mathrm{~m}^{2}$ and $28.9 \mathrm{~m}^{-1}$, respectively.

(2) Permafrost temperature is higher under closed crushed-rocks embankment with wide pavement, increasing to $-0.25^{\circ} \mathrm{C}$ in the 50th year from now, while for closed crushed-rocks embankment with narrow pavement, the same temperature goes up to $-0.3^{\circ} \mathrm{C}$. Permafrost temperature is high in both 


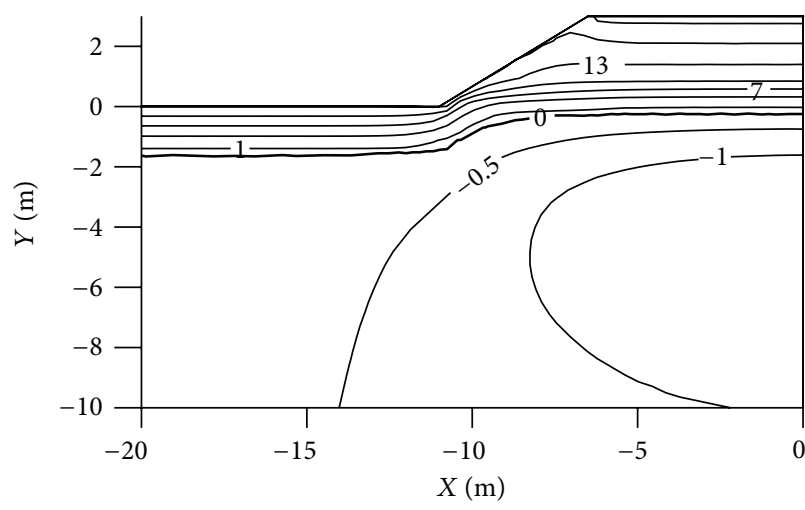

(a) 15 th of July

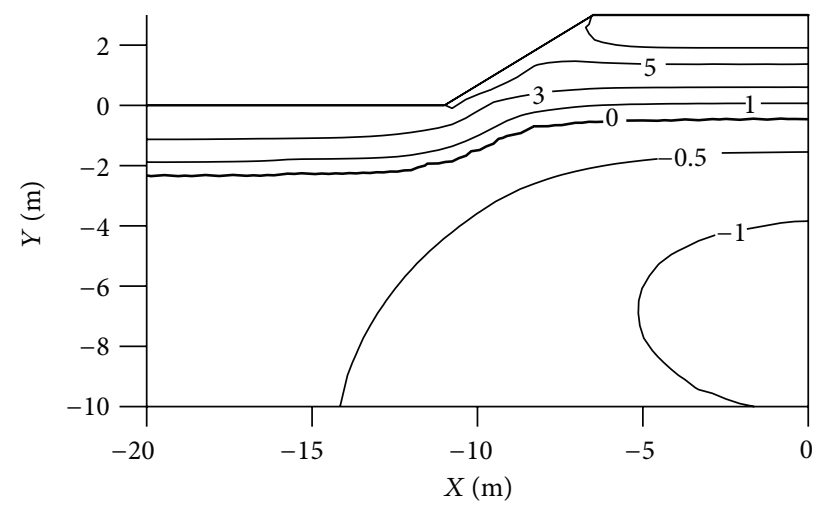

(b) 15 th of October

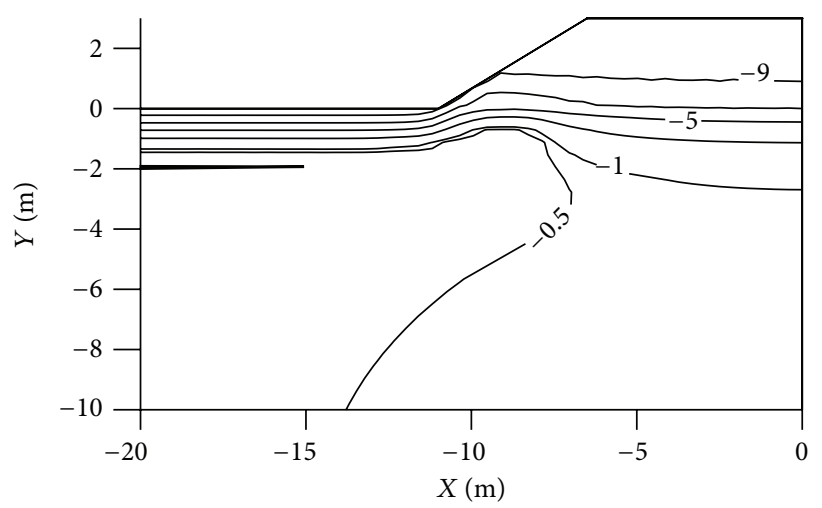

(c) 15 th of January

FIGURE 8: Temperature field of the duct-ventilated and closed crushed-rocks embankment after 50 years of construction.

situations; therefore use of such two embankments is inappropriate, when constructing high-grade roads in permafrost regions.

(3) Duct-ventilated crushed-rocks (closed) embankment can effectively lower the permafrost temperature under it, increasing its permafrost table under the embankment, ensuring long-term stability of the permafrost under the embankment. In consideration of large air temperature rises, the use of such embankment for asphalt high-grade roads in permafrost regions is recommended.

\section{Conflict of Interests}

The authors declare that there is no conflict of interests regarding the publication of this paper.

\section{Acknowledgments}

This work is supported by the National Natural Science Foundation of China (no. 41271080), the Western Project Program of the Chinese Academy of Sciences (KZCX2-XB319), the National key Basic Research Program of China (973 Program) (2012CB026102), and the Funding of the State Key Laboratory of Frozen Soil Engineering (SKLFSE-ZQ-35).

\section{References}

[1] W. Ma, J. Qi, and Q. Wu, "Analysis of the deformation of embankments on the Qinghai-Tibet railway," Journal of Geotechnical and Geoenvironmental Engineering, vol. 134, no. 11, pp. 1645-1654, 2008.

[2] Z.-Z. Sun, W. Ma, and D.-Q. Li, "Ground temperature characteristics of block stone embankment and traditional embankment at Beiluhe along Qinghai-Tibet Railway," Chinese Journal of Geotechnical Engineering, vol. 30, no. 2, pp. 303-308, 2008.

[3] Y. Lai, L. Zhang, S. Zhang, and L. Mi, "Cooling effect of rippedstone embankments on Qing-Tibet railway under climatic warming," Chinese Science Bulletin, vol. 48, no. 6, pp. 598-604, 2003.

[4] G. Y. Li, N. Li, and J. M. Kang, "Study on cooling mechanism of embankment with crushed-stone side-slope along QinghaiTibet railway in permafrost region," Chinese Journal of Rock Mechanics and Engineering, vol. 26, no. 1, pp. 3161-3169, 2007.

[5] M. Zhang, Y. Lai, Z. Liu, and Z. Gao, "Temperature characteristic nonlinear analysis for new-type embankment structures for Qinghai-Tibetan railway under climatic warming," China Civil Engineering Journal, vol. 39, no. 2, pp. 93-101, 2006.

[6] B.-X. Sun, X.-Z. Xu, Y.-M. Lai, S.-J. Wang, and J.-Z. Zhang, "Impact of ballast grain sizes on natural convection cooling effect of embankment in permafrost regions," Chinese Journal of Geotechnical Engineering, vol. 26, no. 6, pp. 809-814, 2004.

[7] W. B. Yu, Y. M. Lai, X. F. Zhang, S. Zhang, and J. Xiao, "Laboratory investigation on cooling effect of coarse rock layer 
and fine rock layer in permafrost regions," Cold Regions Science and Technology, vol. 38, no. 1, pp. 31-42, 2004.

[8] S.-S. He, M.-Y. Zhang, Y. Zhang, Z.-H. Gao, and L. Jin, "Laboratory investigation on cooling characteristics of open block-stone revetment in permafrost regions," Journal of the China Railway Society, vol. 30, no. 4, pp. 54-58, 2008.

[9] Z.-Z. Sun, W. Ma, and D.-Q. Li, "Study of adjusting temperature effect of ripped-rock in-situ," Rock and Soil Mechanics, vol. 27, no. 11, pp. 2001-2004, 2006.

[10] D. A. Nield and A. Bejan, Convection in Porous Media, Springer, New York, NY, USA, 2nd edition, 1999.

[11] L. J. Yang, B. X. Sun, Q. Liu, and X. Z. Xu, "Applicability of the Darcy's law to convection of pore air in crushed/blocked rock embankments," Journal of Glaciology and Geocryology, vol. 29, pp. 8-15, 2007.

[12] X. Y. Kong and J. B. Wu, "A bifurcation study of non-Darcy free convection in porous media," Acta Mechanica Sinica, vol. 34, no. 2, pp. 177-185, 2002.

[13] X. Y. Kong, High Fluid Mechanics of Seepage, University of Science and Technology of China Press, Hefei, China, 1999.

[14] F. J. Wang, Fluid Mechanics of Calculation-CFD Software Principle and Application, Tsinghua University Press, Beijing, China, 2004.

[15] P. Forchheimer, "Wasserbewegung durch Boden," Zeitschrift des Vereins Deutscher Ingenieure, vol. 45, pp. 1782-1788, 1901.

[16] W. F. Li, H. F. Liu, and X. Gong, Fluid Mechanics of Engineering, East China University of Science and Technical Press, Shanghai, China, 2009.

[17] G. Q. Tong, D. Q. Li, and M. Y. Zhang, "Experimental study of ventilation property and parameters of cubic arranged cement balls," Chinese Journal of Rock Mechanics and Engineering, vol. 30, no. 1, pp. 2798-2802, 2011.

[18] L. N. Zhu, "Study of the adherent layer on different types of ground in permafrost regions on the Qinghai-Xizang Plateau," Journal of Glaciology and Geocryology, vol. 10, pp. 8-14, 1988.

[19] N. Fujun, L. Xingfu, M. Wei, W. Qingbai, and X. Jian, "Monitoring study on the boundary thermal conditions of ductventilated embankment in permafrost regions," Cold Regions Science and Technology, vol. 53, no. 3, pp. 305-316, 2008.

[20] E. M. Zang and Z. W. Wu, Permafrost Degradation and Road Engineering, Lanzhou University Press, Lanzhou, China, 1999.

[21] G. D. Cheng, H. Jiang, K. L. Wang, and Q. B. Wu, “Thawing Index and freezing Index on the embankment surface in permafrost regions," Journal of Glaciology and Geocryology, vol. 25, pp. 603-607, 2003.

[22] Z. R. Zhang, Heat Transfer, Higher Education Press, Beijing, China, 1989. 

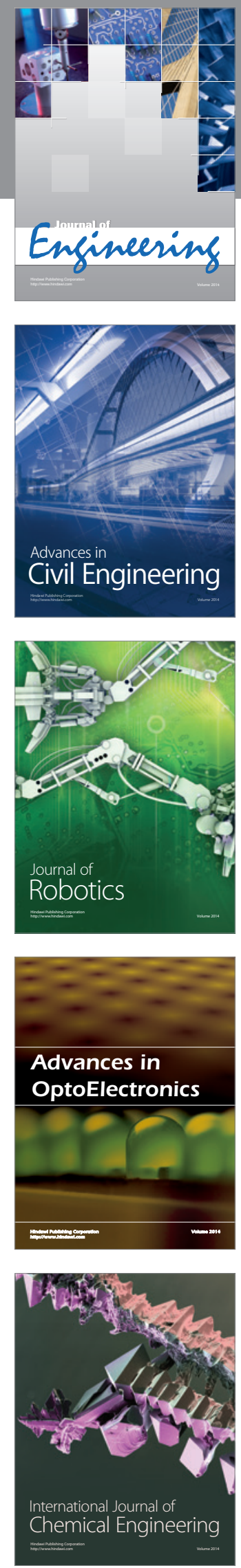

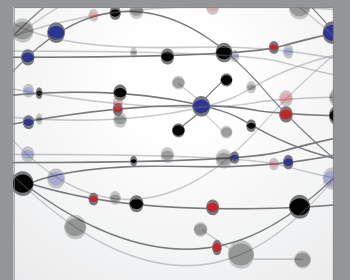

The Scientific World Journal
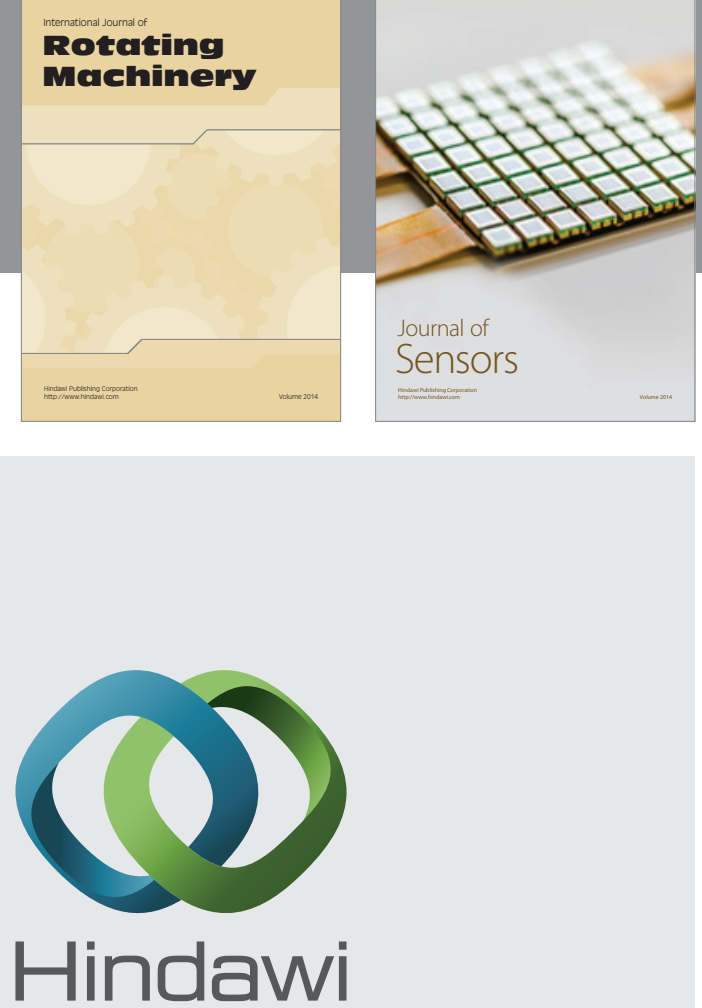

Submit your manuscripts at http://www.hindawi.com
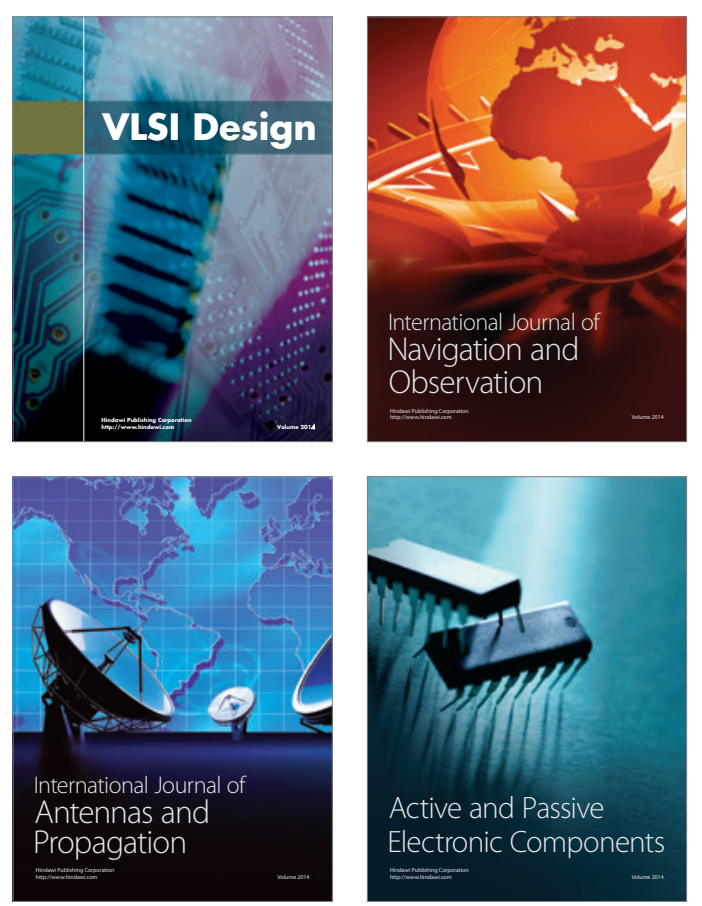
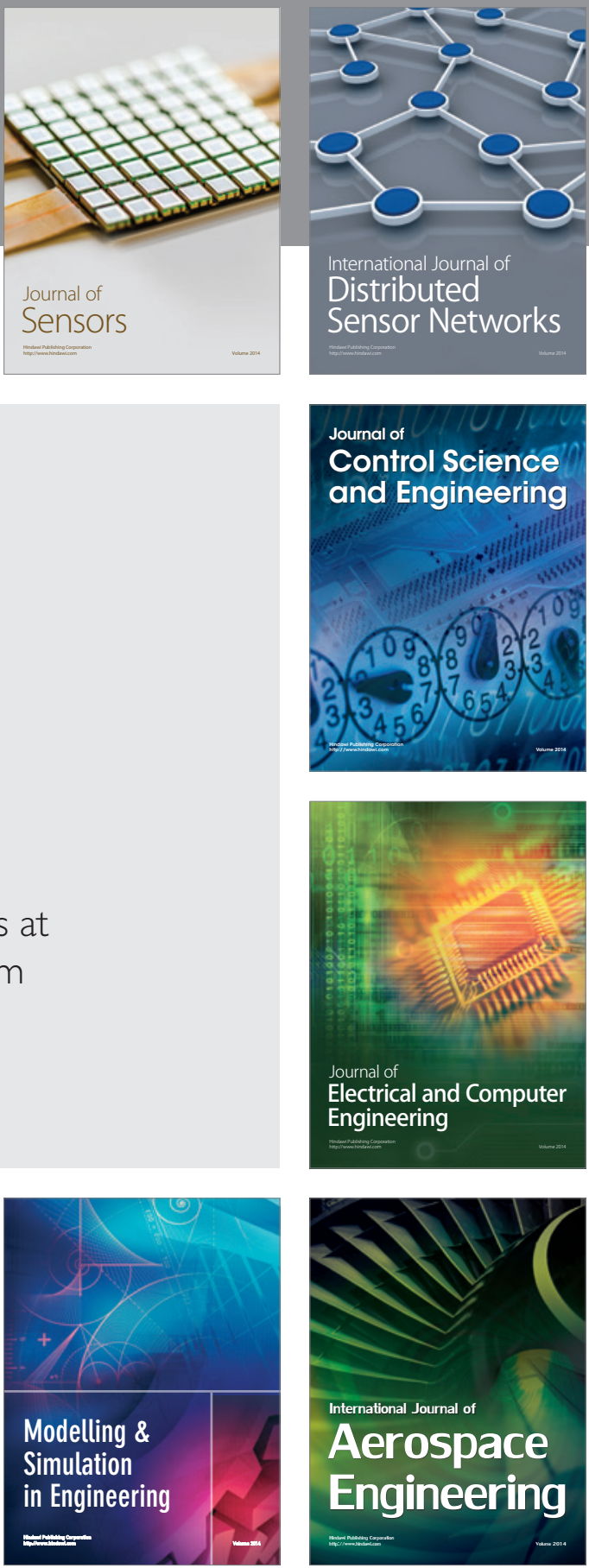

Journal of

Control Science

and Engineering
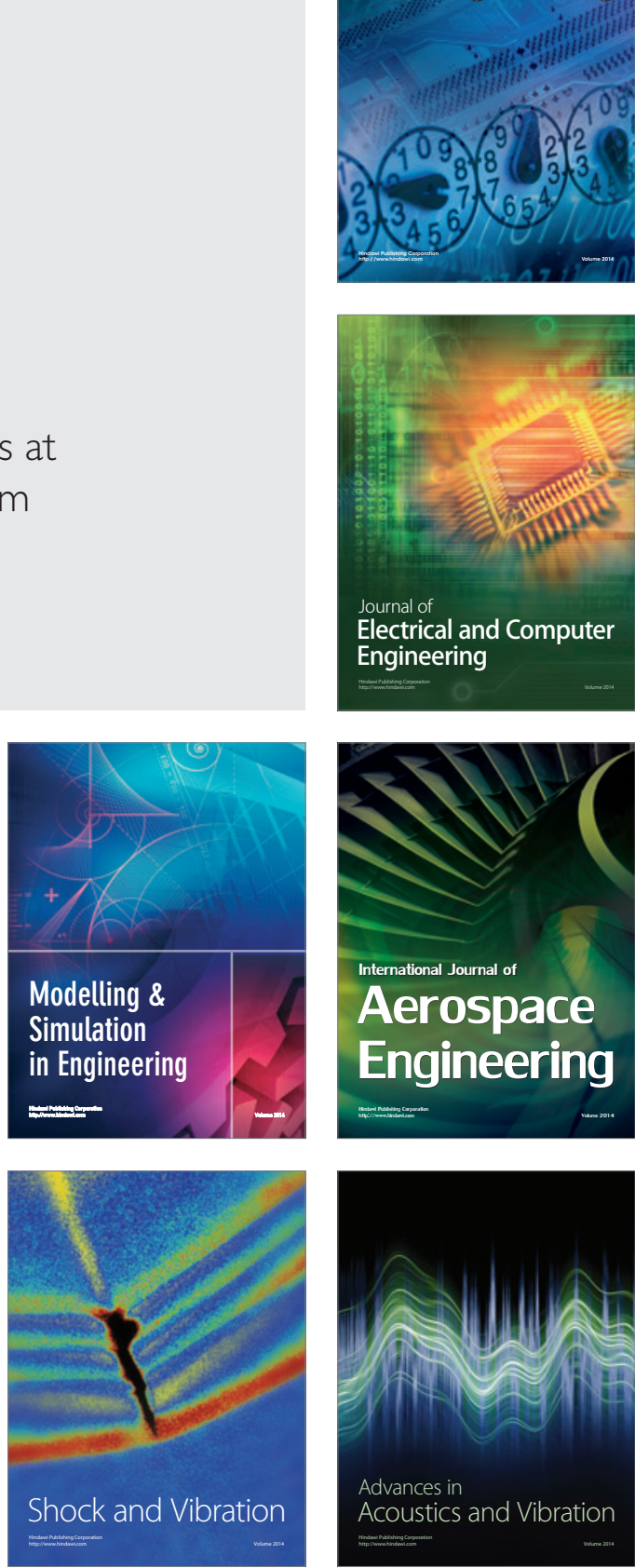